\title{
Cutting model parameters from frame sawing of natural and impregnated Scots pine (Pinus sylvestris L.)
}

\author{
Gerhard Sinn $^{1} \cdot$ Daniel Chuchała ${ }^{2} \cdot$ Kazimierz A. Orlowski $^{2} \cdot$ Piotr Taube $^{3}$
}

Received: 3 September 2019 / Published online: 4 July 2020

(c) The Author(s) 2020

\begin{abstract}
In this paper, absolute and density normalized cutting model parameters of natural and impregnated Scots pine (Pinus sylvestris L.) are shown and a method for the calculation of their corresponding material properties in the principal material directions of wood is presented. The parameters were determined from measurements of cutting power on a sash gang saw, and are in detail the fracture toughness and the shear yield strength of wood. The cutting model used for fitting the data and calculating the parameters is based on a minimum energy criterion originally developed to describe an orthogonal single tooth cutting process where the chip of an isotropic material is built by shear. The effects of impregnation on wood are clearly visible in cutting power and model parameters, where for large chips less power is required compared to natural wood. Impregnated pine wood shows a reduced value of shear yield strength compared to natural pine whilst the correlated fracture toughness increased. The observed behavior might be explained by a lower moisture content of the impregnated pine compared to natural wood. Orthotropic fracture toughness and shear yield strength constants of natural and impregnated Scots pine might be used to predict cutting power for other cutting geometries and processes like circular sawing.
\end{abstract}

\section{Introduction}

The fracture toughness and the shear yield strength in the shear zone are significant parameters to determine the forces and power to cut (Atkins 2009). Atkins theory was successfully used to explain the material dependency of the shear angle in metal cutting as well as in wood cutting along the grain and cutting of composite materials (Atkins 2009). When the chips are not produced in shear but by plastic bending, a model developed by Williams (1998) might be more suitable to describe the cutting process. The model also uses the fracture toughness to describe the energy necessary to separate the chip from the bulk, but the deformation of the chip occurs in bending. Orlowski and Atkins (2007) modified the original shear model based on cutting forces

Gerhard Sinn

gerhard.sinn@boku.ac.at

1 Institute of Physics and Materials Science, University of Natural Resources and Life Sciences, Peter-Jordan-Str. 82, 1190 Vienna, Austria

2 Department of Manufacturing and Production Engineering, Faculty of Mechanical Engineering, Gdansk University of Technology, ul. G. Narutowicza 11/12, Gdansk, Poland

3 SYlVA Ltd. Co. ul, Kościerska 2, 83-441 Wiele, Poland of a single tooth to forecast the cutting power of sawing processes of wood with multiple cutting teeth. This enhancement allowed a more accurate prediction of cutting power compared to previous cutting models, because it considers tool geometry (rake angle), chip forming conditions (shear angle), and material properties of the cut material such as: fracture toughness and shear yield strength in the shear zone (Orlowski et al. 2013).

Krzosek (2009) has shown that strength properties of Pinus sylvestris L. depend on the provenance of the material. In addition, sawing studies on Scots pine wood from various parts of Poland have shown that the cutting power and parameters derived thereof, depend on the provenance as well (Chuchala et al. 2014).

Research made on impregnated pine (Konopka et al. 2018) showed that the electrical resistance of wood might be lowered by the impregnation agent. Adanur et al. (2017) studied the influence of borax and boric acids on oriental beech. Compression test, bending test, and screw holding strength test were performed. The screw holding strength was higher in the impregnated samples compared to the controls, whereas the bending strength and elastic modulus decreased. Percin et al. (2015) studied the combined influence of impregnation with inorganic borates and heat treatment on some mechanical properties of oak. All strength 
parameters decreased with increased temperature of treatment but the losses of samples impregnated with borax were lower than the non-impregnated controls. Orlowski and Dzurenda (2018) studied chip formation on impregnated wood. They found that the impregnation of pine wood had an impact on the shape of the sawdust produced during the cutting process. The observed sawdust had a different size distribution with a slightly higher number of smaller particles (below $125 \mu \mathrm{m}$ ) in case of the impregnated wood, which indicates different mechanical properties. Preliminary cutting experiments on a small number of impregnated samples (Chuchala and Orlowski 2018) have shown that the impregnation process has some influence on the power demand of the cutting process.

From the studied literature, the hypothesis is formulated that wood impregnation affects material properties and therefore the cutting power and the cutting model parameters of pine. Within this experimental work, several scantlings were cut and the cutting model parameters are worked out. The influence of impregnation on the results is discussed and a methodology is presented to generalize the results to other cutting directions and wood species.

\section{Materials and methods}

For the experiments, two groups of Scots pine samples (Pinus sylvestris L.) from Pomeranian region of Poland were prepared. One series was left in its natural state (10 samples) and the second group was impregnated with a wood preservative ( 9 of 10 samples were used for the final analysis, see Table 1). Samples were prepared by the company Sylva Ltd. Co. in Wiele (Poland) in the form of rectangular scantlings with dimensions of $50 \cdot 50 \cdot 500 \mathrm{~mm}^{3}(H \cdot W \cdot L)$.

Samples of wood for cutting experiments were preselected to not include the wood core, i.e. juvenile wood. Juvenile wood is known to be more flexible and less strong than mature wood. For example, Mencuccini et al. (1997) reported a decrease in Young's modulus at lower cambial age of Scots pine and Larson et al. (2001) wrote a literature review on properties and formation of juvenile wood in southern pines, where several distinctive features compared to mature wood are listed.

For the impregnation process, a water-soluble chromate and boron-free wood preservative based on copper complex compounds and a highly effective quaternary ammonium compound, Korasit ${ }^{\circledR}$ KS2 (KG n.d.), manufactured by the company Kurt Obermeier GmbH \& Co. KG, was used. According to the technical datasheet (KG n.d.) of the product, it is designed to protect wood from wood destroying fungi and insects.

Ten samples from each kind of wood were investigated and stored under the same climatic conditions prior to
Table 1 Values of moisture content MC of samples. Sample SOIM-5, marked with a *, was excluded from averaging

\begin{tabular}{lllll}
\hline Impregnated pine wood & & & Natural pine wood \\
\cline { 1 - 2 } \cline { 5 - 5 } Name of sample & $\begin{array}{l}\text { Moisture } \\
\text { content } \\
{[\%]}\end{array}$ & & Name of sample & $\begin{array}{l}\text { Moisture } \\
\text { content } \\
{[\%]}\end{array}$ \\
\hline SOIM-1 & 5.6 & & SONP-2 & 11.9 \\
SOIM-2 & 7.7 & & SONP-5 & 8.5 \\
SOIM-3 & 7.1 & & SONP-6 & 11.2 \\
SOIM-4 & 9.3 & & SONP-7 & 13.9 \\
SOIM-5* & $5.7 *$ & & SONP-9 & 10.7 \\
SOIM-6 & 6.4 & & SONP-11 & 12.6 \\
SOIM-7 & 9.0 & & SONP-12 & 10.7 \\
SOIM-8 & 8.7 & & SONP-13 & 11.7 \\
SOIM-9 & 8.7 & & SONP-14 & 9.3 \\
SOIM-12 & 7.0 & & SONP-17 & 13.3 \\
Average & 7.7 & & & 11.4 \\
Standard deviation & 1.3 & &
\end{tabular}

cutting. Moisture content (MC) of samples was measured with a pin-type moisture meter (Type WRD 100 from TANEL Electronics \& IT General Partnership, Poland, Gliwice) perpendicular to the wood fibre direction according to the specification in the manual. Results are shown in Table 1. Calibration curves were measured to correlate moisture content obtained by the pin-type moisture meter to the gravimetrically measured moisture content. This was necessary to exclude any measurement bias caused by the impregnation process.

Wood raw density was measured gravimetrically after the impregnation process for the natural and the impregnated group of samples.

The values of cutting power were determined from experimental tests, which were carried out on the frame sawing machine PRW15M with elliptical tooth trajectory and a hybrid dynamically balanced driving system (Wasielewski and Orlowski 2002). In the experimental tests, machine settings were applied, which are shown in Table 2 . The only varying cutting parameter was feed speed, which was applied at two levels: $v_{f 1} \approx 0.92 \mathrm{~m} \mathrm{~min}^{-1}$ and $v_{f 2} \approx 1.887 \mathrm{~m} \mathrm{~min}^{-1}$, which corresponds to a feed per tooth $\left(f_{z}\right)$ of $\sim 0.11 \mathrm{~mm}$ and $\sim 0.22 \mathrm{~mm}$, respectively. The actual value of the feed per tooth was computed on the basis of the sawing time and the sample length taken from the plots of time changes of electrical power consumption (Fig. 1). The mean value of feed per tooth $f_{z}$ in $(\mathrm{mm})$ for a sash gang saw is calculated as $\left(v_{f}\right.$ in $\mathrm{m} \mathrm{min}^{-1}$, tooth pitch $P$ and saw frame stroke $H_{F}$ in $\mathrm{mm}$ and $n_{\mathrm{F}}$ in $\mathrm{min}^{-1}$ ): 


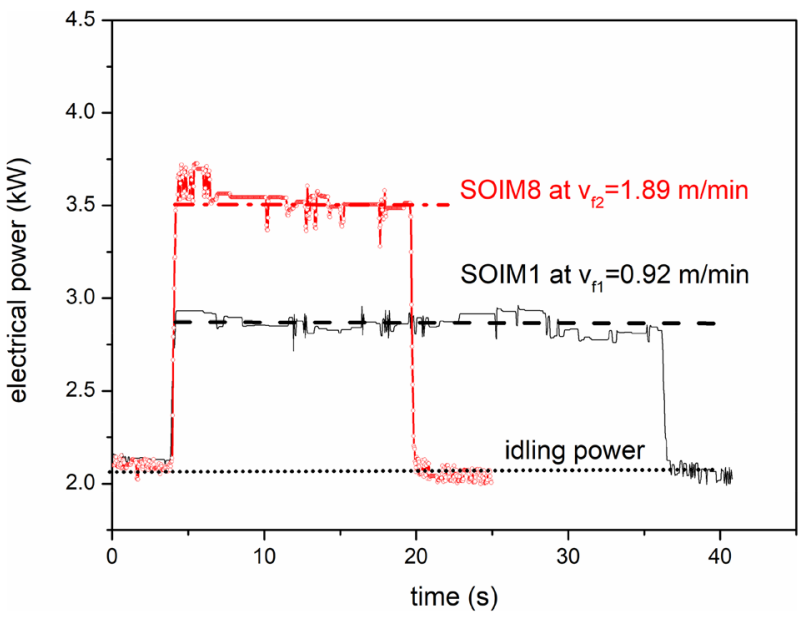

Fig. 1 Changes in electrical power while sawing at two levels of feed speed $v_{\mathrm{f} 1}$ and $v_{\mathrm{f} 2}$ shown for two impregnated samples (SOIM)

Table 2 Tool and machine tool data

\begin{tabular}{lll}
\hline Name of parameter & Symbol [unit] & Value \\
\hline Frame sawing machine PRW15M & & \\
Number of strokes of the saw frame per min & $\mathrm{n}_{\mathrm{F}}\left[\mathrm{min}^{-1}\right]$ & 685 \\
Number of saws in the gang & $\mathrm{m}[-]$ & 5 \\
Average cutting speed & $\mathrm{v}_{\mathrm{c}}\left[\mathrm{m} \cdot \mathrm{s}^{-1}\right]$ & 3.69 \\
Saw frame stroke & $\mathrm{H}_{\mathrm{F}}[\mathrm{mm}]$ & 162 \\
Tension stresses of saw blades in the gang & $\sigma_{\mathrm{N}}[\mathrm{MPa}]$ & 300 \\
Saw blade & & \\
(sharp, with stellite@ tipped teeth) & & \\
Kerf width (overall set) & $\mathrm{S}_{\mathrm{t}}[\mathrm{mm}]$ & 2 \\
Saw blade thickness & $\mathrm{s}[\mathrm{mm}]$ & 0.9 \\
Free length of the saw blade & $\mathrm{L}_{0}[\mathrm{~mm}]$ & 318 \\
Blade width & $\mathrm{b}[\mathrm{mm}]$ & 30 \\
Tooth pitch & $\mathrm{P}[\mathrm{mm}]$ & 13 \\
Tool side rake angle & $\gamma_{\mathrm{f}}\left[{ }^{\circ}\right]$ & 9 \\
Tool side clearance angle & $\alpha_{\mathrm{f}}\left[{ }^{\circ}\right]$ & 14 \\
\hline
\end{tabular}

$f_{z}=1000 \frac{v_{f} \cdot P}{n_{F} \cdot H_{F}}$

where $v_{\mathrm{f}}$ in $\mathrm{m} \mathrm{min}^{-1}$ is calculated as follows:

$v_{f}=\frac{L_{p}}{t_{c}}$

$L_{\mathrm{p}}$ is length of the sample in meter, and $t_{\mathrm{c}}$ is the real cutting time in minutes taken from the plot, for example Fig. 1.

The value of the average cutting power $\bar{P}_{c}$ was calculated as the difference of the mean total power during cutting $\bar{P}_{c T}$ and the average idle power $\bar{P}_{i}$ of the main propulsion (Orlowski 2010):
$\bar{P}_{c}=\bar{P}_{c T}-\bar{P}_{i}$

The average idle power of the main propulsion of frame saw PRW15-M was determined immediately before the onset of cutting from the data collected of the idle running. This procedure allowed for changes of the average idling power due to, for example, a change in viscosity of the oil in gearboxes of the main propulsion during operation. Values of the average cutting power in a working stroke $\bar{P}_{c w}$ (calculated variable) are twice the values of the average cutting power $\bar{P}_{c}$ (average power of the working and the idle stroke) due to non-cutting upwards movement of the saw in the second part of the symmetric motion of the sawing frame (Orlowski 2010) (see Fig. 2):

$\bar{P}_{c w}=2 \bar{P}_{c}$

Taking into account the model of cutting forces presented by Atkins (2003) and the discussion on the parameters, fracture toughness and shear yield strength from cutting experiments (Atkins 2005), the average value of cutting power in the working stroke $\bar{P}_{c w}$ (Fig. 2) for a number of $m$ saw blades and $n_{t}$ teeth in action can be written as follows (Orlowski 2010; Orlowski and Palubicki 2009):

$\bar{P}_{c w}=\mathrm{m}\left[n_{t} \frac{\tau_{\gamma} S_{t} \epsilon}{Q} v_{c} f_{z}+n_{t} \frac{R S_{t}}{Q} v_{c}\right]=\left(m \frac{H_{P}}{P}\right)\left(\frac{S_{t}}{Q}\right)\left[\tau_{\gamma} \epsilon f_{z}+R\right] v_{c}$

Summarizing the parameters and dividing by the cutting speed gives the average cutting force in the working stroke $\bar{F}_{c w}$ :

$\bar{F}_{c w}=\left(m \frac{H_{P}}{P}\right) F_{c}$

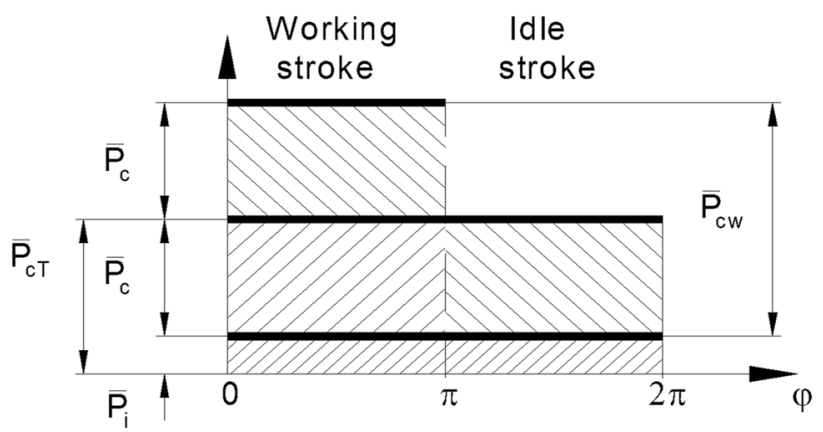

Fig. 2 Graphical representation of the power contributions in the frame saw machine cycle (working stroke +idle stroke) (Orłowski 2010): $\bar{P}_{c}$ represents the average cutting power contribution during the whole cycle, the average cutting power in a working stroke $\bar{P}_{c w}=2 \cdot \bar{P}_{c}$ during the working stroke and $\bar{P}_{c w}=0$ during the idle stroke (idle power $\bar{P}_{i}$, mean total power $\bar{P}_{c T}$ ) 
where $n_{t}=\frac{H_{P}}{P}$ is the average number of teeth being in contact with the kerf for a single saw and a certain workpiece height $H_{P}$ (cutting depth in mm), $f_{z}$ - is feed per tooth (equal to the uncut chip thickness $h$ in $\mathrm{mm}$ ), $\varepsilon$ - is the shear strain along the shear plane, $Q-$ is the friction correction factor (Atkins 2003, 2005; Orlowski et al. 2013).

For the needs of this work, values of the shear angle were calculated using friction coefficients from the literature with the minimum cutting energy criterion proposed by Atkins (2003, 2005) (see Eq. 7). This was necessary because the feeding force is not available from the experiment to calculate the friction coefficient. Therefore, an average friction coefficient for intermediate moisture contents of $\mu=0.6$ was used (Glass and Zelinka 2010; Svensson et al. 2009).

$$
\begin{aligned}
{[1-} & \left.\frac{\sin \beta \sin \Phi}{\cos \left(\beta-\gamma_{f}\right) \cos \left(\Phi-\gamma_{f}\right)}\right]\left[\frac{1}{\cos ^{2}\left(\Phi-\gamma_{f}\right)}-\frac{1}{\sin ^{2} \Phi}\right] \\
= & -\left[\cot \Phi+\tan \left(\Phi-\gamma_{f}\right)+Z\right] \\
& \left\{\frac{\sin \beta}{\cos \left(\beta-\gamma_{f}\right)}\left[\frac{\cos \Phi}{\cos \left(\Phi-\gamma_{f}\right)}+\frac{\sin \Phi \sin \left(\Phi-\gamma_{f}\right)}{\cos ^{2}\left(\Phi-\gamma_{f}\right)}\right]\right\}
\end{aligned}
$$

where $\beta$ is friction angle, referred to as $\beta=\tan ^{-1} \mu$.

For large chip thicknesses, the shear angle $\Phi$ converts to values which can be determined in a simplified way from geometry and coefficient of friction with the equation proposed by Merchant (Orlowski and Atkins 2007; Orlowski and Palubicki 2009). This value was used as initial guess for $\Phi$, together with a guess for $Z$ (see Eq. 8), to minimize Eq. (7), which cannot be solved explicitly for $\Phi$.

$\mathrm{Z}=\frac{R}{\tau_{\gamma}} \frac{1}{f_{z}}$
The so calculated shear angle, considered as constant for the next step of the fitting procedure, is then used to calculate the linear regression line of the cutting force as a function of the uncut chip thickness $f_{z}$ (Eq. 7).

$\bar{F}_{c w}\left(f_{z}\right)=a_{1} f_{z}+a_{0}$

From the regression coefficients $a_{0}$ and $a_{1}$, new values for the fracture toughness and the shear yield strength can be calculated.

Repeating this procedure with the new values of shear yield strength and fracture toughness, starting with the calculation of the shear angles (Eq. 7), provides an iterative method for the determination of all two independent model parameters. The third unknown parameter, i.e. the shear angle $\Phi$ is a dependent variable and is determined from Eq. 7. The iteration is stopped when the regression coefficient does not change anymore within a pre-defined limit.

Methods of determining these properties on the basis of cutting data were minutely described in the papers by Hlaskova et al. (2015), Orlowski and Atkins (2007) and Orlowski and Palubicki (2009).

In this case, values of fracture toughness $R_{\perp}$ and shear yield strength $\tau_{\gamma \perp}$ for perpendicular direction of cutting speed $v_{c}$ to wood direction $\Phi_{\mathrm{G}-\mathrm{vc}}=90^{\circ}$ (Fig. 3) are obtained.

\section{Results and discussions}

\subsection{Moisture content}

The moisture content of the two groups of samples, after correction with the calibration curves, is shown in Table 1. A one-way ANOVA analysis, performed with R Core Team (R Core Team 2018), showed that the average moisture (a)

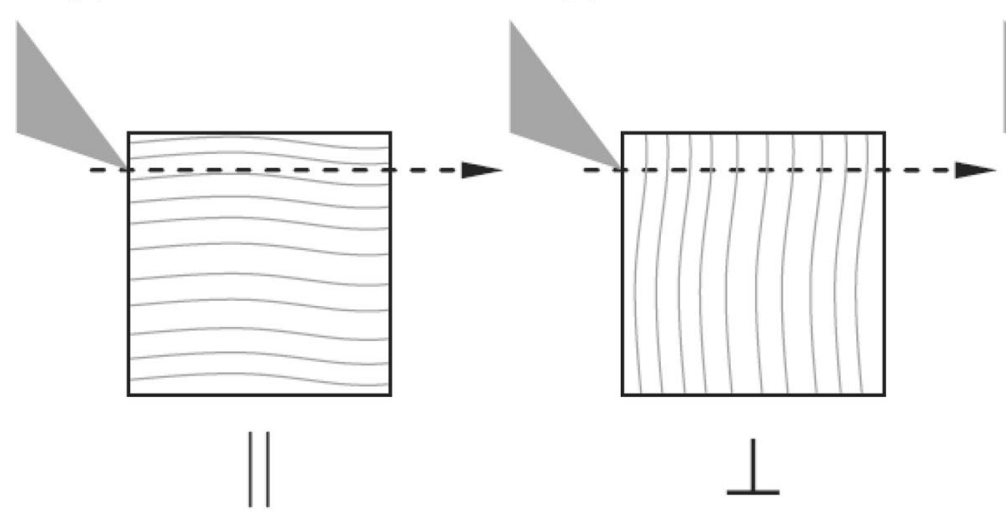

(c)

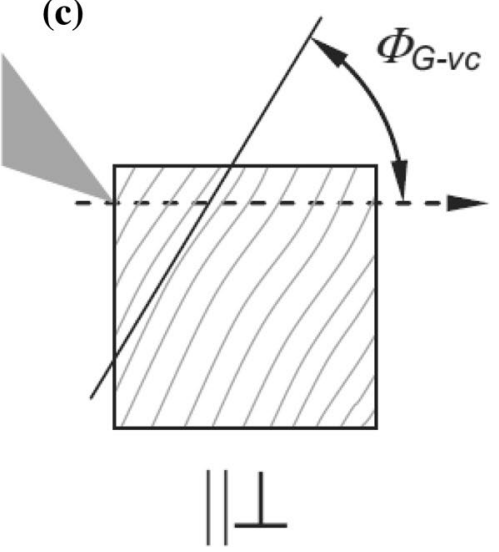

Fig. 3 Cutting speed directions when orthogonal cutting of orthotropic materials; axial II cutting along fibres a, perpendicular $\perp$ cutting across fibres $\mathbf{b}$ and intermediate $\| \perp$ direction $\mathbf{c}$ (Orlowski et al. 2017) 
content of the impregnated wood is $7.7 \pm 1.3 \%$ and it is statistically significantly lower than the moisture content of natural wood $11.4 \pm 1.7 \%$. The difference in moisture content is about $3.7 \%$.

\section{Density}

The measured raw density of natural wood samples $\rho=554.3 \pm 60.8 \mathrm{~kg} \cdot \mathrm{m}^{-3}$ was slightly higher than those of impregnated wood $\rho=533.4 \pm 48.6 \mathrm{~kg} \cdot \mathrm{m}^{-3}$ (without sample SOIM-5). Combining the measurements of wood moisture contents and wood raw densities, oven-dry densities were calculated:

$\rho_{\text {od }}=\frac{\rho}{1+u}$

Care was taken to have normal-distributed oven-dry densities with equal oven-dry mean densities for all four cutting cases to avoid any unwanted bias from the densities in the power measurements. Therefore, sample SOIM 5 was excluded from further analysis. Figure 4 summarizes the oven-dry densities in boxplots to illustrate the homogeneity of the data.

\section{Cutting power and parameter extraction}

To reduce the scatter of the data and to provide more general results, cutting power and forces were normalised by the oven-dry density. This method allowed to calculate densitynormalised values of fracture toughness and shear yield strength, which in the future might be compared to results

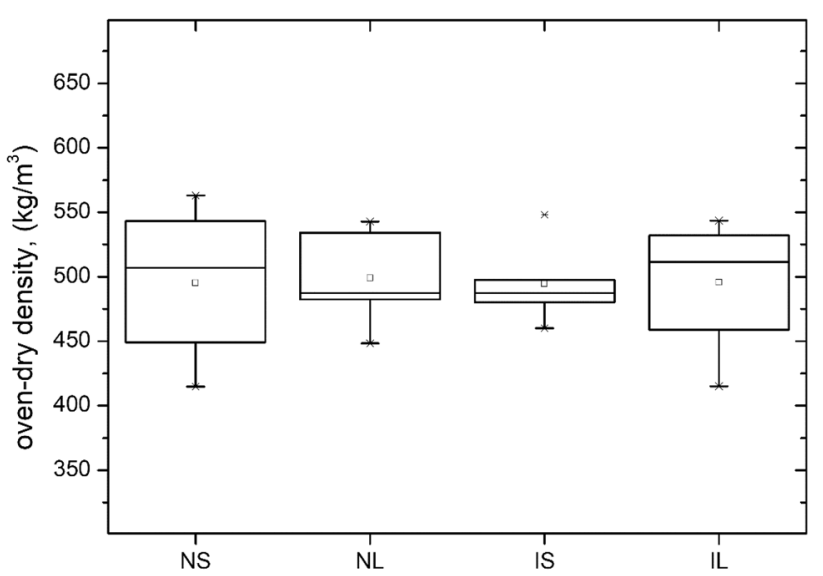

Fig. 4 Boxplot of oven-dry densities for the four groups of cutting conditions:

Natural pine and small feed per tooth NS, natural pine and large feed per tooth NL and impregnated pine small feed per tooth IS and large feed per tooth IL

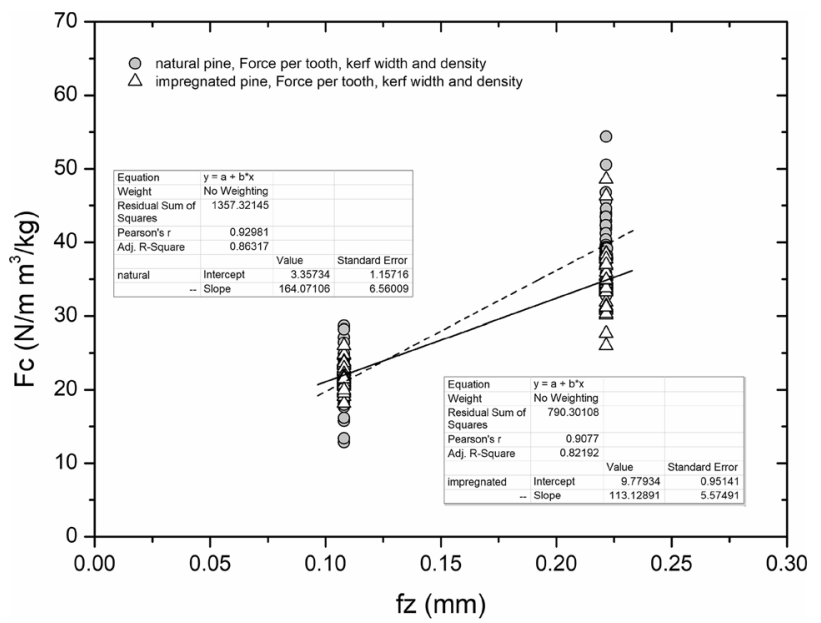

Fig. 5 Cutting forces for one tooth normalized by the density of the samples and kerf width as a function of feed per tooth (uncut chip thickness) during cutting of impregnated pine (triangles, SOIM) and natural pine wood (filled circles, SONP). Regression lines show linear fit of impregnated wood (solid line and lower table) and natural pine (dashed line and upper table)

gained from other wood species. Figure 5 shows changes in cutting force for one single tooth normalized by the average oven dry densities of the specimens while cutting of impregnated (triangles) and natural pine (circles). The power signals were split in ten equally spaced sections in time, and averages were calculated for each cutting period. This procedure is favourable for the following regression analysis, because more data points can be used for the analysis, and outliers can be excluded efficiently. For example, knots and other defects of wood can have a significant effect on the local cutting power, since these tissues usually have different grain orientations and densities (Caceres et al. 2018).

In Fig. 5, linear regression lines are also drawn and the coefficients are presented thereof. Additionally, coefficients of determination $r^{2}$ for each model are shown. The value of adjusted $r^{2}=0.82$, for the regression line created on the basis of data obtained from the process of cutting impregnated pine wood (SOIM), is significant (level of significance $\alpha=0.05, n=90$ ) (Sachs 1991). For natural wood, the coefficient of determination reaches $r^{2}=0.86(n=100)$ and also is highly significant. The coefficients of determination were higher than without normalisation by the densities, which justifies the procedure.

From the regression parameters in Fig. 5 and the average shear angle $\Phi$ and shear strain $\varepsilon$ from Table 3 and curve fitting procedure, density normalised fracture toughness $R^{*}{ }_{\perp}$ and shear strength $\tau_{y \perp}^{*}$ can be calculated with their corresponding standard errors.

For impregnated wood at larger chip thickness, a decrease in cutting force was observed compared to normal wood. 
Table 3 Average shear angle $\Phi$, average friction correction $Q$, average shear strain $\varepsilon$, and density normalized fracture toughness $R_{\perp}{ }^{*}$ and shear yield strength $\tau_{\gamma \perp}{ }^{*}$ of impregnated and natural pine wood with standard errors

\begin{tabular}{lllllll}
\hline Symbol & Type of wood & $\begin{array}{l}\Phi, \\
\left({ }^{\circ}\right)\end{array}$ & $\begin{array}{l}Q, \\
(-)\end{array}$ & $\begin{array}{l}\varepsilon, \\
(-)\end{array}$ & $\begin{array}{l}\boldsymbol{R}_{\perp}^{*} / \boldsymbol{\rho}, \\
\left(\mathrm{J} \cdot \mathrm{m} \cdot \mathrm{kg}^{-1}\right)\end{array}$ \\
\hline SOIM & Impregnated pine wood & 29.42 & $0.709 \pm 0.014$ & $2.15 \pm 0.07$ & $\begin{array}{l}\boldsymbol{\tau}_{\gamma \perp}^{*} / \boldsymbol{\rho}, \\
\left(\mathrm{MPa} \cdot \mathrm{m}^{3} \cdot\right. \\
\left.\mathrm{kg}^{-1}\right)\end{array}$ \\
SONP & Natural pine wood & 32.81 & $0.671 \pm 0.005$ & $1.99 \pm 0.01$ & $2.25 \pm 0.78$ & 0.052 \\
\hline
\end{tabular}

Table 4 Oven-dry density $\rho$, fracture toughness $R_{\perp}$ and shear yield strength $\tau_{\gamma \perp}$ of impregnated and natural pine wood with standard errors

\begin{tabular}{lllll}
\hline Symbol & Type of wood & $\begin{array}{l}\rho_{\text {od }}, \\
\left(\mathrm{kg} \cdot \mathrm{m}^{-3}\right)\end{array}$ & $\begin{array}{l}\boldsymbol{R}_{\perp}, \\
\left(\mathrm{J} \cdot \mathrm{m}^{2}\right)\end{array}$ & $\begin{array}{l}\boldsymbol{\tau}_{\gamma_{\perp}}, \\
(\mathrm{MPa})\end{array}$ \\
\hline SOIM & $\begin{array}{c}\text { Impregnated pine } \\
\text { wood }\end{array}$ & $494.9 \pm 39.4$ & $3432 \pm 333$ & $18.47 \pm 0.91$ \\
SONP & Natural pine wood & $497.2 \pm 46,9$ & $1121 \pm 386$ & $27.48 \pm 1.10$ \\
\hline
\end{tabular}

The average values of fracture toughness $R^{*}{ }_{\perp}$ and the average values of shear yield strength in shear zone $\tau^{*}{ }_{y \perp}$ (Table 3), both normalized by the wood densities (marked by stars*), were determined from iterative fitting procedure. The significance of the differences between the average values of fracture toughness and shear yield strength in the shear zone was checked using the Student's t-test (Sachs 1991). For both studied properties, the differences between the values obtained for impregnated pine wood and natural pine are significant (Table 4).

The results of the density-normalised fracture toughness of natural wood and impregnated wood differ significantly in their absolute values. The impregnated wood shows 3.1-times higher normalized fracture toughness than normal wood. The absolute values for the fracture toughness obtained from cutting of natural pine perpendicular to the grain $R_{\perp}=1.12 \mathrm{~kJ} / \mathrm{m}^{2}$ are in the range of the values reported in the literature. Orlowski et al. (2017) report a value of $R_{\perp}=1.3 \mathrm{~kJ} / \mathrm{m}^{2}$ for natural pine.

At the same time, the normalised shear strength of impregnated pine reaches only $68 \%$ percent of the strength of natural pine. The absolute values for natural wood from this work $\tau_{\gamma \perp}=27.5 \mathrm{MPa}$ are higher than the values reported, for example, by Orlowski et al. (2017), i.e. $\tau_{\gamma \perp}=17.31 \mathrm{MPa}$ ), for natural wood. The values from the literature are closer to the values gained for impregnated pine $\tau_{\gamma \perp}=18.5 \mathrm{MPa}$.

To explain this behaviour the influence of the impregnation process might be explained as a first approximation by the lower moisture content of the impregnated wood. It is well known from the literature that, in general, stiffness as well as strength properties, decrease with increasing moisture content (Wood Handbook - Wood as an Engineering
Material 2010). Taking a closer look, the energy release rate, which is the equivalent value of the fracture toughness in cutting, might increase with moisture content, for example for splitting along the grain (Reiterer and Tschegg 2002), whereas the shear strength might have a maximum around 10\% moisture content (Kollmann and Cote 1968).

A decrease in the cutting forces with moisture content below approx. 10\% moisture content was already documented by Kivimaa (1952) for pine wood cut in the same direction as in this article. This decrease is more pronounced at higher cutting depths (see Kivimaa 1952), as has also been observed in this study.

Therefore, this atypical behaviour regarding the strength properties as a function of moisture content has already been reported in the literature. Nevertheless, the impregnation process might have also modified the friction behaviour of the cutting process and thus, the shear angle, which cannot be addressed with the available data.

To compare the cutting parameters with the parameters from mechanical testing, the parameters have to be transferred into the natural material coordinate system. This involves simple renaming in case of fracture toughness, because separation occurs in the radial-tangential plane, which corresponds to the LR-crack propagation system (Bodig and Jayne 1982). In case of the shear strength, a coordinate transformation from the property measured in the shear plane into the material coordinate system has to be made. The shear plane for this cutting operation is tilted against the perpendicular to the grain orientation by the shear angle, $\Phi$. The transformation of strength properties is usually made for wood with Hankinson's formula (Bodig and Jayne 1982; Kollmann and Cote 1968; Kretschmann 2010; Lang et al. 2000; Logsdon et al. 2014; Mantilla Carrasco and Rodo Mantilla 2016; Mascia and Nicolas 2012).

$\tau_{\Phi}=\frac{\tau_{\|} \tau_{\perp}}{\tau_{\|} \sin ^{k} \Phi+\tau_{\perp} \cos ^{k} \Phi}$

For the exponent, $\mathrm{k}=2$ is generally proposed in the literature. To calculate the shear strength in the material directions, an additional value for the shear strength, either parallel or perpendicular to the grain orientation, is necessary. For this purpose, literature value of pine for shear in the grain direction is taken $\left(\tau_{\|}=8.9 \mathrm{MPa}\right.$ between $8-10 \%$ 
moisture content) (Krajewski et al. 2016) and the shear strength perpendicular to the wood grain direction is calculated (The opposite way of calculation would be better, but reliable shear strength values perpendicular to the grain could not be found for pine). Assuming, that the change in strength is moisture induced, it is rational to assume that the ratio of shear strength of natural wood to impregnated wood (ratio $=1.48$ ) can also be applied to the ratio of shear strength from the literature in grain direction. Therefore, the resulting shear strength in grain direction used was $\tau_{\|}=8.9 \mathrm{MPa}$ for impregnated wood and $\tau_{\|}=13.2 \mathrm{MPa}$ for natural wood. Using these values and the experimental results of the shear strength in $\Phi$-direction, values perpendicular to the grain were calculated. Results are $\tau_{\perp}=32.2 \mathrm{MPa}$ for impregnated wood and $\tau_{\perp}=47.9 \mathrm{MPa}$ for natural wood. The value for impregnated pine wood is in good agreement with data presented by Kollmann and Cote (1968) for natural pine. They report for $\tau_{\|}=10.2 \mathrm{MPa}$ for the parallel shear strength and $\tau_{\perp}=32.2 \mathrm{MPa}$ for the average perpendicular shear strength of pine. The shear strength observed for natural pine $\tau_{\perp}=47.9 \mathrm{MPa}$ was 1.5 -times the value reported by Kollmann and Cote (1968) for natural pine.

The obtained values of fracture toughness and shear yield strength of pine wood normalized by the oven-dry densities might be used for the prediction of cutting forces and power of other cutting processes acting in the same working plane (Chuchala and Orlowski 2018; Orlowski et al. 2013) and might be suitable also for other softwoods with different densities.

\section{Conclusion}

The average values of fracture toughness and shear yield strength were calculated from cutting experiments of natural and impregnated pine. Force data were normalized by oven-dry density to calculate density- normalized parameters, which might be used for other softwood species with similar moisture contents as well.

For impregnated pine wood, a fracture toughness of $R_{\perp}=3432 \pm 333 \mathrm{~J} \cdot \mathrm{m}^{-2}$ and for natural pine wood $R_{\perp}=1121 \pm 386 \mathrm{~J} \cdot \mathrm{m}^{-2}$ were found. Despite of high variation in the raw data, the differences between both parameters were significant.

The average values of shear yield strength for impregnated $\left(\tau_{\gamma \perp}=18.47 \pm 0.91 \mathrm{MPa}\right)$ and natural $\left(\tau_{\gamma \perp}=27,48 \pm 1.10\right.$ $\mathrm{MPa}$ ) pine wood are also significantly different from each other. Using Hankinson's equation, strength values parallel and perpendicular to fibre direction were approximated and material parameters in the standard coordinate system used for wood could be calculated. This procedure might be generalized, if more cutting directions are studied to obtain a full set of material parameters.
It could be shown that the impregnation process reduced the wood moisture content; the change in cutting parameters and behaviour might be mainly explained by this reduction. The higher shear strength of natural wood at higher moisture contents compared to impregnated wood with lower moisture content might be explained by a maximum of the shear strength around $10 \%$ moisture content.

Acknowledgements Open access funding provided by University of Natural Resources and Life Sciences Vienna (BOKU). Financial support of BMBWF through OEAD within the project PL 06/2019 and NAWA (Polish National Agency for Academic Exchange) within the project PPN/BIL/2018/1/00100/U/00001 is gratefully acknowledged.

\section{Compliance with ethical standards}

Conflict of interest On behalf of all authors, the corresponding author states that there are no conflicts of interest.

Open Access This article is licensed under a Creative Commons Attribution 4.0 International License, which permits use, sharing, adaptation, distribution and reproduction in any medium or format, as long as you give appropriate credit to the original author(s) and the source, provide a link to the Creative Commons licence, and indicate if changes were made. The images or other third party material in this article are included in the article's Creative Commons licence, unless indicated otherwise in a credit line to the material. If material is not included in the article's Creative Commons licence and your intended use is not permitted by statutory regulation or exceeds the permitted use, you will need to obtain permission directly from the copyright holder. To view a copy of this licence, visit http://creativecommons.org/licenses/by/4.0/.

\section{References}

Adanur H, Fidan M, Yaşar Ş (2017) The technological properties of oriental beech (fagus orientalis lipsky) impregnated with boron compounds and natural materials. BioResources 12(1):1647-1661

Atkins A (2003) 'Modelling metal cutting using modern ductile fracture mechanics: quantitative explanations for some longstanding problems.' Int J Mech Sci 45(2):373-396

Atkins A (2005) Toughness and cutting: a new way of simultaneously determining ductile fracture toughness and strength. Eng Fract Mech 72(6), 849-860. Prospects in Fracture Papers from a Conference held to Celebrate the 65th Birthday of Professor J.G. Williams, FRS, FREng Imperial College London, July 2003

Atkins T (2009) 3 - Simple orthogonal cutting of floppy, brittle and ductile materials. Butterworth-Heinemann, Oxford

Bodig J, Jayne BA (1982) Mechanics of wood and wood composites. Van Nostrand, Reinhold

Caceres CB, Uliana L, Hernandez RE (2018) 'Orthogonal cutting study of wood and knots of white spruce.' Wood Fiber Sci 50(1):55-65

Chuchala D, Orlowski KA (2018) Forecasting values of cutting power for the sawing process of impregnated pine wood on band sawing machine. Mechanik pp. 766-768

Chuchala D, Orlowski KA, Sandak A, Sandak J, Pauliny D, Baranski J (2014) The effect of wood provenance and density on cutting forces while sawing scots pine (Pinus sylvestris L.). BioResources 9(3):5349-5361

Glass SV, Zelinka SL (2010) Wood handbook - wood as an engineering material, centennial edition edn, U.S. Department of Agriculture, 
Forest Service, Forest Products Laboratory, techreport Chap. 4: Moisture Relations and Physical Properties of Wood, pp. 4-1--4-19

Hlaskova L, Orlowski KA, Kopecky Z, Jedinak M (2015) Sawing processes as a way of determining fracture toughness and shear yield stresses of wood. BioResources 10(3):5381-5394

Kurt Obermeier GmbH \& Co. KG (n.d.) Korasit ${ }^{\circledR}$ KS2, wood preservative for applications as per DIN 68800-3

Kivimaa E (1952) Die Schnittkraft in der Holzbearbeitung. (The cutting force in wood processing). Holz Roh- Werkst 10(3):94-108. https://doi.org/10.1007/BF02608840

Kollmann FF, Cote WA (1968) Principles of wood science and technology. I solid wood. Springer, Berlin

Konopka A, Baranski J, Orlowski K, Szymanowski K (2018) The Effect of Full-Cell Impregnation of Pine Wood (Pinus sylvestris L.) on changes in electrical resistance and on the accuracy of moisture content measurement using resistance meters. BioResources 13(1):1360-1371

Krajewski A, Kozakiewicz P, Witomski P (2016) Shear strength of scots pine (Pinus sylvestris L.) from the historical buildings. Wood Res 61(5):845-849

Kretschmann DE (2010), Wood Handbook - Wood as an Engineering Material, centennial edition edn, U.S. Department of Agriculture, Forest Service, Forest Products Laboratory, techreport Chap. 5 Mechanical Properties of Wood, pp. 5-1-5-46

Krzosek S (2009) Timber strength grading of Pinus Sylvestris L. using different methods (in Polish: Wytrzymałościowe sortowanie polskiej sosnowej tarcicy konstrukcyjnej różnymi metodami). Wydawnictwo SGGW Warszawa p. 127p

Lang E, Bejo L, Szalai J, Kovacs Z (2000) Orthotropic strength and elasticity of hardwoods in relation to composite manufacture. Part I. Orthotropy of shear strength. Wood Fiber Sci 32(4):502-519

Larson PR, Kretschmann DE, Clark A III, Isebrands JG (2001), Formation and properties of juvenile wood in southern pines, Technical report, Forest Products Laboratory

Logsdon NB, Finger Z, Henriques de Jesus JM (2014) Influence of the angle between applied force and wood grain direction on shear. Cienc Florest 24(4):969-978

Mantilla Carrasco EV, Rodo Mantilla JN (2016) 'Influence of slope of grain in shear strength of wood'. Cienc Florest 26(2):535-543

Mascia NT, Nicolas EA (2012) Evaluation of Tsai-Wu criterion and Hankinson's formula for a brazilian wood species by comparison with experimental off-axis strength tests. Wood Mat Sci Eng 7(1):49-58. https://doi.org/10.1080/17480272.2012.654820

Mencuccini M, Grace J, Fioravanti M (1997) Biomechanical and hydraulic determinants of tree structure in Scots pine: anatomical characteristics. Tree Physiol 17(2):105-113

Orlowski KA (2010) The fundamentals of narrow-kerf sawing: the mechanics and quality of cutting. Publishing House of the Technical University in Zvolen, Technical University in Zvolen
Orlowski KA, Atkins A (2007) Determination of the cutting power of the sawing process using both preliminary sawing data and modern fracture mechanics. In: Navi P, Guidoum A (eds), Proceedings of the third international symposium on wood machining. Fracture mechanics and micromechanics of wood and wood composites with regard to wood machining, EPFL, Presses Polytechniques et Universitaires Romandes, Lausanne

Orlowski KA, Dzurenda L (2018) The effect of full-cell impregnation of pine wood (pinus sylvestris 1.) on the fine dust content during sawing on a frame sawing machine. Chip and Chipless Woodworking Processes pp 131-137

Orlowski KA, Ochrymiuk T, Atkins A, Chuchala D (2013) Application of fracture mechanics for energetic effects predictions while wood sawing. Wood Sci Technol 47(5):949-963

Orlowski KA, Ochrymiuk T, Sandak J, Sandak A (2017) Estimation of fracture toughness and shear yield stress of orthotropic materials in cutting with rotating tools. Eng Fract Mech 178:433-444

Orlowski KA, Palubicki B (2009) Recent progress in research on the cutting processes of wood. A review COST Action E35 20042008: Wood machining - micromechanics and fracture. Holzforschung 63(2):181-185

Percin O, Sofuoglu SD, Uzun O (2015) Effects of boron impregnation and heat treatment on some mechanical properties of Oak (Quercus petraea Liebl.) Wood. BioResources 10(3):3963-3978

$\mathrm{R}$ Core Team (2018) $R$ : a language and environment for statistical computing, R Foundation for Statistical Computing, Vienna, Austria. https://www.R-project.org/

Reiterer A, Tschegg S (2002) The influence of moisture content on the mode I fracture behaviour of sprucewood. J Mater Sci 37(20):4487-4491

Sachs L (1991), Angewandte Statistik, (Applied statistics) (In German), 9th edn, Springer-Verlag, Berlin

Svensson BA, Nyström S, Gradin PA, Höglund H (2009) Frictional testing of wood-initial studies with a new device. Tribol Int 42(1):190-196

Wasielewski R, Orlowski K (2002) Hybrid dynamically balanced saw frame drive. Holz Roh- Werkst 60(3):202-206

Williams JG (1998) Friction and plasticity effects in wedge splitting and cutting fracture tests. J Mater Sci 33(22):5351-5357. https:// doi.org/10.1023/A:1004490015211

Wood Handbook - Wood as an Engineering Material (2010) centennial edition edn, U.S. Department of Agriculture, Forest Service, Forest Products Laboratory

Publisher's Note Springer Nature remains neutral with regard to jurisdictional claims in published maps and institutional affiliations. 